\title{
A Waste Reverse Logistics Model Importing Full Information Sharing
}

\author{
Yufang Chiu and Ruei-Heng Dai
}

\begin{abstract}
In order to reduce environmental pollution, waste returns and recycling has become a trend. But the process of waste management such as waste collection, treatment and distribution between supply and demand that lacking of information often leads to more wastes. This study took the full information sharing into account, reducing wastes between the members of the supply chain. In addition, because all the process of waste treatment will deal with the cost and risk, this study thus discussed waste management system under uncertainties. Providing information to business decision-makers, the purpose of this study is to discuss the retail price of reusable waste which returned to the market and the amount of waste collection that affects the profit. The result shows that demand quantity and price factors would affect the amount of waste collection and the profit; where the waste collection risk is a significant factor, thus this study indicated that the management needs to consider risk factors in the waste collection system.
\end{abstract}

Index Terms-Full information sharing, reverse logistics, risk, wastes.

\section{INTRODUCTION}

The articles consulted from this study mostly focus on the selection of the site of factory of waste treatment and optimization problem of the network configuration to waste management [1], [2], seldom discussed the waste treatment problem in reverse logistics. Because wastes may have potential danger to human health or environment by improper management, Sheu [3] considered total reverse logistics activity cost and relevant risks (exposure, storage, transportation) at the same time in the research, and proved that reverse logistics join dangerous waste management can decrease $58 \%$ costs effectively.

Agrawal et al. [4] mentioned that information sharing can really reduce bullwhip effect effectively, and then reduce the relevant cost and raise the performance. Therefore, assuming a given contaminated area, this study applied reverse logistics system, and integrated a circumstance of full information sharing in order to develop a waste reverse logistics profit model. The purpose is to discuss the retail price of reusable waste which returned to the market and the amount of waste collection that affects the profit, and provide information to business decision-making.

Manuscript received August 25, 2012; revised October 26, 2012

The authors are with the Department of Industrial and Systems Engineering, Chung Yuan Christian University, Chung Li, Taiwan 32023 (e-mail: daivdchiu@cycu.edu.tw).

\section{LITERATURE REVIEW}

\section{A. Waste}

$\mathrm{Hu}$ et al. [5] showed that Hazardous-waste reverse logistics may be useful for solving waste-induced environmental pollution problems that accompany high-technology industrial development. Pokharel and Mutha [6] developed a reverse logistics management model for solid waste, mainly regulated the interaction between transportation planning, inventory control, and production planning, and paid the utmost attention to the uncertainty of the whole system.

\section{B. Reverse Logistics}

Cruz-Rivera and Ertelb [7] showed that reverse logistics not only can increase the value of the recycling products but also reduce the disposal cost that must be spent through the reverse logistics. Wilcox [8] used Markov chain process to combine the operation system of the reverse logistics, and contribute to management and development of the reverse logistics, while making enterprise understand short-term demand and long-term mobile demand of planning.

\section{Risk}

Because the wastes are dangerous, manufacturer must do a risk assessment in order to understand the safety in the course of dealing with the dangerous items. Erkut and Ingolfsson [9] used transportation shortest path problem to develop a new model, and combined assessment to transportation risk, in order to meet the customer's demand.

\section{Information Sharing}

Kong and Hao [10] thought that the main reason of too much order and inventory increase in the supply chain comes from the lack of information, causing inventory to accumulate, capacity planning imbalance and the whole profit is reduced etc. Agrawal et al. [4] mentioned that information sharing can really reduce bullwhip effect effectively, and then reduce the relevant cost and improve the performance. Sahin and Robinson [11] mentioned that when information is shared more completely, supplier and manufacturer will be able to plan together, achieve the goal of lowering costs under no inventory risk.

\section{RESEARCH METHOD AND PROCEDURE}

\section{A. Research Method}

This study consulted Agrawal et al., Sheu, and Zhang et al. [3], [4], [12], and divided the insufficient places of 
above-mentioned literature into two parts. The risk project built by Sheu [3] was integrated with the hazard estimation of waste by Zhang et al. [12], and increasing the integrality of risk. This study combined risk projects such as collecting, treatment and transportation, etc. In order to solve the bullwhip effect among wastes in the process of supply chain, this study consulted Agrawal et al., Kong and Hao, and Sahin and Robinson [4], [10], [11] for the advantage of information sharing, constructing a total profit model with complete information sharing situation.

\section{B. Assumptions}

1) Because of the variation of wastes, this study considered multiple periods and multiple kinds of treatment and distributing system.

2) Since that the hazard is already quite low after the waste treatment, so the wastes were divided to recycling for reuse and not recycling for reuse.

3) Although inventory cost will be different for different kind of waste, this study supposes that as a fixed value because external operation condition has not changed.

4) Only dealing with the wastes of a particular area, the maximum handling capacity of the reverse logistics center will not exceed the producing amount actually.

5) As to each period, the total inventory quantity of the treated and untreated wastes should not exceed the limit in the reverse logistics center.

6) The quantity of wastes in the process of collection, treatment, distribution, and storage are all the positive values.

\section{Notation}

$\theta_{n} \quad$ Unit retail price of the nth recyclable and reusable waste (decision variable) (dollars)

$X n(t)$ The collecting amount of nth waste at the $t$ period (the decision variable) (ton)

$M n(t)$ The treatment amount of the waste $\mathrm{n}$ at the period $\mathrm{t}$ (ton)

$T \quad$ Number of period $(T=1,2,3, . ., n)$

$N \quad$ Number of kinds of wastes $(N=1,2,3, . ., n)$

$C_{\mathrm{n}}^{\mathrm{j}} \quad$ The unit cost of activity $\mathrm{j}$ for the waste $\mathrm{n}, j=M$ (treatment), W (disposal), C (collection) (dollars / ton)

$T R C_{n}{ }^{R}$ The unit transportation cost for recycling and reuse of the waste $\mathrm{n}$ (ton - kilometer)

$T R C_{n}{ }^{W}$ The unit transportation cost for disposal of the waste $n$ (ton - kilometer)

$d_{n}{ }^{R} \quad$ The total transportation distance for recycling and reuse of the waste $\mathrm{n}$ (kilometer)

$d_{n}{ }^{W} \quad$ The total transportation distance for disposal of the waste $\mathrm{n}$ (kilometer)

$V \quad$ The profit of recycled products sold in market (dollars)

$\rho_{n}{ }^{m} \quad$ The unit risk cost of activity $\mathrm{m}$ for the waste $n, m=E$ (exposure), C (collection), S (storage), M (treatment) (dollars / ton)

$\eta_{n}{ }^{R} \quad$ The unit transportation risk cost in recycling and reuse for the waste $\mathrm{n}$ ( dollars / ton - $\mathrm{km}$ )

$\eta_{n}{ }^{W}$ The unit transportation risk cost in final disposal for the waste $\mathrm{n}$ (dollars / ton - kilometer)

$\lambda_{n}{ }^{W} \quad$ The ratio of disposed items after treatment versus the overall items before treatment for the waste $n$
$M_{n}^{c a p}$ The maximum treatment (processing) capacity (ton)

$R_{\text {com }}{ }^{C}$ The minimum total waste collection amount by considering operating profit in the reverse logistics center (ton)

$R_{\text {gov }}{ }^{C}$ The minimum total waste collection amount based on the environmental laws (ton)

$R_{\text {com }}{ }^{M}$ The minimum total waste treatment amount by considering operating profit (ton)

$R_{\text {gov }}{ }^{M}$ The minimum total waste treatment amount based on the government environmental laws (ton)

$\sigma \quad$ The maximum loading of a vehicle (ton)

$\mu_{t} \quad$ The seasonal index in the period $\mathrm{t}$

$\alpha \quad$ The demand sensitivity factor, $0<|\alpha|<1$

$\beta \quad$ The waste price sensitivity factor

$\gamma \quad$ The added value because of full information sharing

\section{Research Model}

This study consulted Agrawal et al., Sahin and Robinson, and $\mathrm{Wu}$ and Cheng [4], [11], [13], assuming that the waste production amount at a specific area $Q_{n}(t)$ is equal to the total collecting amount in waste collecting center $X_{n}(t)$, and untreated or treated waste inventories are equal to zero. The waste amount which can be recycled and reused $D_{n}(t)$ and the production amount of waste $n Q_{n}(t)$ is the market recycling ratio $p$ following all processing activities. By constructing the multi-type and multi-period waste decision model, this study determined the optimum retail price for recycled wastes and the optimum collecting amount in waste collecting center. The total profit with full information sharing is as follows:

$$
\begin{gathered}
\mathrm{TTV}=\sum_{n=1}^{N} \sum_{t=1}^{T}\left(\begin{array}{l}
\theta_{n}^{R}\left[p \cdot \alpha \cdot X_{n}(t-1)-p \beta\left(\theta_{n}^{R}\right)+p \cdot \gamma\right] \\
-\left[\alpha \cdot X_{n}(t-1)-\beta\left(\theta_{n}^{R}\right)-\gamma\right] \cdot\left[C_{n}^{C}+\rho_{n}^{C}\right] \\
-M_{n}(t) \cdot\left[C_{n}^{M}+\frac{\eta_{n}^{W} \cdot d_{n}^{W}}{\sigma}\right] \\
-\eta_{n}^{R} \cdot\left\{\frac{\left[p \cdot \alpha \cdot X_{n}(t-1)-p \beta\left(\theta_{n}\right)+p \cdot \gamma\right] \cdot d_{n}^{R}}{\sigma}\right\}
\end{array}\right\} \\
-\sum_{n=1}^{N} \sum_{t=1}^{T}\left\{\left[p \cdot \alpha \cdot X_{n}(t-1)-p \beta\left(\theta_{n}\right)+p \cdot \gamma\right] \cdot T R C_{n}^{R} \cdot d_{n}^{R}\right\} \\
-\sum_{n=N_{r}+1}^{N} \sum_{t=1}^{T}\left\{\left[\lambda_{n}^{W} \cdot M_{n}(t)\right] \cdot\left[C_{n}^{W}-T R C_{n}^{W} \cdot d_{n}^{W}\right]\right\}
\end{gathered}
$$

Then, the second partial derivative of the total profit function versus $\theta_{n}$ is given as: $\partial^{2} \mathrm{TTV} / \partial \theta_{n}^{2}=-2 \beta p$. According to this study $\beta$ and $p$ are positive value, so $\partial^{2} \mathrm{TTV} / \partial \theta_{n}^{2}<0$, which expresses that equation (1) is a concave downward function with a relatively maximum value. Next, the optimal retail price is solved by letting the first partial derivative of the total profit function versus $\theta_{n}$ equal to 0 , as shown in equation (2).

$$
\theta_{n}^{*}=\frac{1}{2} \sum_{t=1}^{T}\left\{\sum_{n=1}^{N}\left[\frac{\alpha \cdot X_{n}(t-1)}{\beta}+\frac{C_{n}^{C}+\rho_{n}^{C}}{p}+\frac{\eta_{n}^{R} \cdot d_{n}^{R}}{\sigma}\right]+\sum_{n=1}^{N_{t}}\left(T R C_{n}^{R} \cdot d_{n}^{R}\right)\right\}+\frac{\gamma}{\beta}
$$

Next, importing the optimal retail price into the collection equations, the optimal collection amount is obtained as in equation (3).

$$
X_{n}(t)^{*}=\frac{\beta \mu_{t} \cdot\left\{\sum_{n=1}^{N}\left(\frac{C_{n}^{C}+\rho_{n}^{C}}{p}+\frac{\eta_{n}^{R} \cdot d_{n}^{R}}{\sigma}\right)-\sum_{n=1}^{N_{F}}\left(T R C_{n}^{R} \cdot d_{n}^{R}\right)\right\}}{\mu_{t}(\alpha-2)+t \alpha\left(2 t \mu_{t-1}-1\right)}
$$


In the constraints, the lower limit of total wastes collected and treatment amount under government environmental laws and operating profit, and the capacity limit in treatment amount are:

$$
\begin{gathered}
\sum_{n=1}^{N} \sum_{t=1}^{T} X_{n}(t) \geq \max \left\{R_{c o m}^{C}, R_{\text {gov }}^{C}, 0\right\}, \quad \forall n, t \\
\sum_{n=1}^{N} \sum_{t=1}^{T} M_{n}(t) \geq \max \left\{R_{c o m}^{M}, R_{g o v}^{M}, 0\right\}, \quad \forall n, t \\
\sum_{n=1}^{N} \sum_{t=1}^{T} M_{n}(t) \leq M_{n}^{c a p}, \quad \forall n, t
\end{gathered}
$$

In next section, this study not only discussed and verified the model thoroughly, but also added government environmental laws and the requirements limits in reverse logistics center to the total profit model, to prove the feasibility of this model.

\section{MODEL ANALYSISI AND VERICATION}

\section{A. Numerical Example}

This study referred to Agrawal et al., Hu et al., Sheu, and Zhang et al. [4], [5], [3], [12] for the relevant data, including parameters varied with period $t=\{1,2,3,4\}$; parameters varied with waste type $N=\{1,2,3,4\}$; parameters not varied with period $(T)$ and the waste type $(N)$. Substituting parameters into constraints, the result showed that the variables of this study are all in the limit range. Thus substituting the above parameters into the optimal retail price $\theta_{n}{ }^{*}$ and optimal collection amount $X_{n}(t)^{*}$ and the total profit function, when $\theta_{n}{ }^{*}$ equals to 262.422 and $X_{n}(t)^{*}$ equals to 423.021, the maximum total profit $\left(\mathrm{TTV}^{*}\right)$ is 256392.012 .

\section{B. Sensitivity Analysis}

According to the numerical example in previous section and varying the range decision variables $\theta_{n}{ }^{*}$ and $X_{n}(t)^{*}$ to $\pm 30 \%$, this study explored the behaviors of the total profit model. The results shows that the five parameters $\alpha, \beta, \rho_{n}{ }^{c}$, $\eta_{n}{ }^{R}$, and $d_{n}{ }^{R}$ all have notable effects on decision variables $\left(\theta_{n}{ }^{*}\right.$, $\left.X_{n}(t)^{*}\right)$ and the total profit $\left(\mathrm{TTV}^{*}\right)$, where the risk cost of unit waste collection has most significant effect. The above findings verified the importance of the parameters and the necessity of including risk in this study.

\section{Summary}

The sensitivity factor of the demand, sensitivity factor of the waste price, and the waste unit collection cost have most significant impact on the total profit, because these three parameters will all influence the amount of waste collection, and the income of reverse logistics center increases when the collected amount is improved, and then the total profit increases.

\section{CONCLUSION AND Future Study}

This study applied the wastes to reverse logistics mechanism, and used the information permeability in information sharing into the model. The result of the sensitivity analysis showed that, demand and price factor have significant impacts on waste collecting amount and total profit; where the waste unit collecting risk is the most obvious one, and the waste price sensitivity factor is also

significant. The results showed the necessity of considering risks in waste collecting process in this study. This study proposes the following directions for future study.

1) Future models may discuss and analyze wastes from different industries.

2) Future study may collect data by surveys from related industries to combine theory and practice.

\section{ACKNOWLEDGMENT}

The Authors want to express gratitude to the National Science Council, Taiwan (NSC 100-2221-E-033-031-) for its financial support on this study.

\section{REFERENCES}

[1] P. K. Ahluwalia and A. K. Nema, "Multi-objective reverse logistics model for integrated computer waste management," Waste Management and Research, vol. 24, no. 6, pp. 514-527, 2006.

[2] S. Alumura and B. Y. Kara, "A new model for the hazardous waste location-routing problem," Computers \& Operations Research, vol. 34, no. 5, pp. 1046-1423, 2007.

[3] J. B. Sheu, "A coordinated reverse logistics system for regional management of multi-source hazardous wastes," Computers and Operations Research, vol. 34, pp. 1442-1462, 2007.

[4] S. Agrawal, R. N. Sengupta, and K. Shanker, "Impact of information sharing and lead time on bullwhip effect and on-hand inventory," European Journal of Operational Research, vol. 192, pp. 576-593, 2009.

[5] T. L. Hu, J. B. Sheu, and K. H. Huang, "A reverse logistics cost minimization model for the treatment of hazardous wastes," Transportation Research Part E, vol. 38, pp. 457-473, 2002.

[6] S. Pokharel and A. Mutha, "Perspectives in reverse logistics: a review, Resources," Conservation and Recycling, vol. 53, no. 4, pp. 175-182, 2009.

[7] R. C. Riveraa and J. Ertelb, "Reverse logistics network design for the collection of end-of-life vehicles in Mexico," European Journal of Operational Research, vol. 196, no. 3, pp. 930-939, 2009.

[8] N. T. Wilcox, "Stochastically more risk averse, a contextual theory of stochastic discrete choice under risk," Journal of Econometrics, vol. 162, no. 1, pp. 89-104, 2011.

[9] E. Erkut and A. Ingolfsson, "Transport risk models for hazardous materials: revisited," Operations Research Letters, vol. 33, pp. 81-89, 2005.

[10] Z. Kong and G. Hao, "The effect of information sharing on inventory in a two-stage supply chain," IEEE, pp. 2883-2886, 2007.

[11] F. Sahin and E. P. Robinson, "Information sharing and coordination in make-to-order supply chains," Journal of Operations Management, vol. 23, no. 6, pp. 579-598, 2005.

[12] Y. M. Zhang, G. H. Huang, and L. Heb, "An inexact reverse logistics model for municipal solid waste management systems," Journal of Environmental Management, vol. 92, pp. 522-530, 2010.

[13] Y. N. Wu and T. C. E. Cheng, "The impact of information sharing in a multiple-echelon supply chain," International Journal of Production Economics, vol.115, no. 1, pp.1-11, 2008.

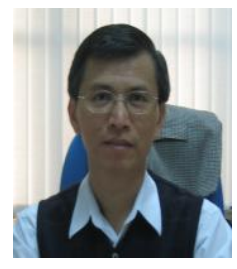

management.

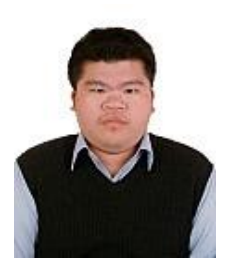

Yufang Chiu is currently an assistant professor in Dept. of Industrial and Systems Engineering at Chung Yuan Christian University, Taiwan. He received his Ph.D. and M.S. in Industrial Engineering from Texas Tech University and a B.S. IE from Chung Yuan Christian University. His research interests include production and operations management, reverse logistics, total quality management and engineering

Ruei-Heng Dai is currently a master student in Dept. of Industrial and Systems Engineering at Chung Yuan Christian University, Taiwan. 